Marine Biology

November 2008 ; Volume 156 (1) : Pages 25-38

http://dx.doi.org/10.1007/s00227-008-1062-4

(c) 2008 Springer. Part of Springer Science+Business

Media

The original publication is available at http://www.springerlink.com
Archimer, archive institutionnelle de l'Ifremer http://www.ifremer.fr/docelec/

\title{
Effect of reproduction on escape responses, metabolic rates and muscle mitochondrial properties in the scallop Placopecten magellanicus
}

\author{
Edouard Kraffe ${ }^{1,2,{ }^{*}}$, Réjean Tremblay ${ }^{3}$, Sonia Belvin ${ }^{3}$, Jean-René LeCoz $^{4}$, Yanic Marty ${ }^{1}$ and Helga \\ Guderley $^{2}$
}

\author{
${ }^{1}$ Unité mixte CNRS 6521, Université de Bretagne Occidentale, C.S. 93837, 29238 Brest Cedex 3, France \\ ${ }^{2}$ Département de Biologie, Université Laval, Québec, QC, G1K 7P4, Canada \\ ${ }^{3}$ Institut des Sciences de la Mer, 310 allée des Ursulines, Rimouski, QC, G5L 3A1, Canada \\ ${ }^{4}$ UMR 100 Physiologie et Ecophysiologie des Mollusques Marins, Ifremer, Centre de Brest, B.P. 70, 29280 \\ Plouzané, France
}

*: Corresponding author : Kraffe E., email address : Edouard.Kraffe@univ-brest.fr

\begin{abstract}
:
In scallops, gametogenesis and spawning can diminish the metabolic capacities of the adductor muscle and reduce escape response performance. To evaluate potential mechanisms underlying this compromise between reproductive investment and escape response, we examined the impact of reproductive stage (pre-spawned, spawned and reproductive quiescent) of the giant scallop, Placopecten magellanicus, on behavioural (i.e., escape responses), physiological (i.e., standard metabolic rates and metabolic rates after complete fatigue) and mitochondrial capacities (i.e., oxidative rates) and composition. Escape responses changed markedly with reproductive investment, with spawned scallops making fewer claps and having shorter responses than pre-spawned or reproductive-quiescent animals. After recuperation, spawned scallops also recovered a lower proportion of their initial escape response. Scallop metabolic rate after complete fatigue $\left(\mathrm{VO}_{2 \max }\right)$ did not vary significantly with reproductive stage whereas standard metabolic rate $\left(\mathrm{VO}_{2 \mathrm{~min}}\right)$ was higher in spawned scallops. Thus spawned scallops had the highest maintenance requirements $\left(\mathrm{VO}_{2 \min } / \mathrm{VO}_{2 \max }\right)$. Maximal capacities for glutamate oxidation by muscle mitochondria did not change with reproductive stage although levels of ANT and cytochromes as well as cytochrome $C$ oxidase (CCO) activity did. Total mitochondrial phospholipids, sterols and the proportion of phospholipid classes differed only slightly between reproductive stages. Few modifications were detected in the fatty acid (FA) composition of the phospholipid classes except in cardiolipin (CL). In this class, prespawned and spawned scallops had fairly high proportions of 20:5n-3 whereas this FA in reproductivequiescent scallops was threefold lower and 22:6n-3 was significantly higher. These changes paralleled the increases in CCO activity and suggest an important role of $\mathrm{CL}$ on the modifications of CCO activity in scallops. However, mitochondrial properties could not explain the decreased recuperation ability from exhausting exercise in spawned scallops. Shifts in maintenance requirements $\left(\mathrm{VO}_{2 \min } / \mathrm{VO}_{2 \max }\right)$ and aerobic scope $\left(\mathrm{VO}_{2 \max }-\mathrm{VO}_{2 \min }\right)$ provided the best explanation for the impact of reproduction on escape response performance.
\end{abstract}

Keywords: mitochondria, reproduction, scallops, muscle, escape response, metabolic rate, cytochrome C oxidase, phospholipids, plasmalogens, fatty acids, sterols, Placopecten magellanicus. 


\section{Introduction}

The requirements of broadcast spawning lead many marine invertebrates to invest so heavily in gametogenesis and spawning that reproduction represents a major stress (Barber and Blake 1991). Given the material and energetic costs of gametogenesis and spawning, metabolic expenditures are likely to change considerably during the reproductive cycle, particularly in species with a high reproductive output. In scallops, gonadal maturation and spawning lead to a negative energetic balance, a generally diminished physiological condition and a decreased capacity to recover from exhausting exercise (Barber and Blake 1985; Brokordt et al. 2000a; Brokordt et al. 2000b). Thus, scallops face a compromise between two major components of their fitness: reproductive success and individual survival.

In scallops, the striated adductor muscle is one of the largest soft tissues and has as its primary role the rapid movement of valves during escape responses. The capacities of the adductor muscle are thus important for survival during encounters with predators. In many scallop species, the energetic reserves of the adductor muscle are depleted during gonadal maturation and spawning (Barber and Blake 1981; Barber and Blake 1991; Brokordt and Guderley 2004). At the same time, the glycolytic and aerobic capacity of the adductor muscle declines, which could explain reductions in the scallops' swimming ability, and particularly in their capacity to recuperate from exhaustive exercise (Brokordt et al. 2000a; Brokordt et al. 2000b; Brokordt and Guderley 2004). The impact of the reproductive cycle upon escape response performance could also reflect the instantaneous metabolic costs of reproductive investment. Indeed, the gametogenetic cycle of scallops accentuates seasonal changes in metabolic rate with the highest rates occurring during reproductive months and the lowest rates during winter quiescence (Shumway et al. 1988). Thus, the metabolic costs of 
51 reproductive investment and spawning could reduce aerobic scope and slow aerobic 52 recuperation.

53 Rapid valve movements (claps) in scallops are primarily fueled by phosphoarginine, 54 with subsequent recovery using anaerobic glycolysis and then oxidative metabolism. In 55 Placopecten magellanicus and Argopecten irradians concentricus, $70 \%$ of the ATP required 56 for exhaustive escape activity is derived from phosphoarginine, with only $30 \%$ arising from 57 anaerobic glycolysis and octopine generation (Thompson et al. 1980; de Zwaan et al. 1980; 58 Livingstone et al. 1981; Chih and Ellington 1986). Phosphoarginine levels decrease as a 59 function of the number of claps (Livingstone et al. 1981; Bailey et al. 2003). The complete 60 restoration of phosphoarginine pools after exhaustiing swimming requires aerobic metabolism 61 (Livingstone et al. 1981), presumably relying upon ATP production by adductor muscle 62 mitochondria (Guderley et al. 1995). Both muscle glycolytic capacities and the oxidative 63 capacities of muscle mitochondria change with the reproductive cycle in Euvola ziczac and 64 Chlamys islandica, decreasing in animals that have invested extensively in reproduction 65 (Boadas et al. 1997; Brokordt et al. 2000a). Thus, muscle mitochondria can be considered as

key organelles in covering the high energy demand of aerobic recuperation in scallops. Any limitation of their oxidative capacity could hinder aerobic metabolism and could explain the impact of reproductive investment on aerobic recuperation.

Mitochondrial capacities can be changed by shifts in their protein and phospholipid components. Alterations in phospholipid head groups and acyl chain compositions modify the molecular activities of respiratory chain components (Hazel 1972a; Hazel 1972b). Mitochondrial membrane proteins can have specific requirements for phospholipid head group arrangements and FA in their proximity (Clandinin et al. 1985; Berger et al. 1993; Schlame et al. 2000). Thus, modifications in membrane lipid composition, even of minor 
75 phospholipid classes during the reproductive cycle, could underlie changes in mitochondrial 76 oxidative capacity with the reproductive cycle.

77 This study examined potential mechanisms underlying the compromise between 78 locomotor performance and reproductive investment in the giant scallop, $P$. magellanicus, by 79 evaluating changes in the aerobic power budget and mitochondrial capacities with 80 reproductive investment. To this end, we compared scallops sampled in their natural habitat 81 at 3 reproductive stages (pre-spawned, spawned and reproductive-quiescent). We 82 characterized their escape responses, recuperation from exhaustion, aerobic power budget, 83 muscle mitochondrial capacities and mitochondrial composition. To evaluate how respiratory 84 capacity could be associated with swimming ability, particularly in the capacity to recuperate 85 from exhausting exercise, oxygen uptake was measured at rest in non-feeding animals $86\left(\mathrm{VO}_{2} \mathrm{~min}\right)$ and during aerobic recovery from exhausting exercise $\left(\mathrm{VO}_{2} \mathrm{max}\right)$. We further 87 examined properties of adductor muscle mitochondria as possible drivers of whole animal 88 metabolic rate and recuperation from exhausting exercise. We determined maximal rates of 89 glutamate oxidation, levels of adenine nucleotide translocase (ANT), concentrations of 90 cytochromes $\mathrm{A}, \mathrm{B}, \mathrm{C}$ and $\mathrm{C}_{1}$, activity of cytochrome $C$ oxidase $(\mathrm{CCO})$ and proportions of the 91 phospholipid classes and subclasses as well as their FA compositions. By examining 92 performance and structure at these levels, we sought to evaluate whether changes in scallop 93 escape response performance with reproductive investment were due to their aerobic power 94 budget or to their muscle mitochondrial properties. 


\section{Materials and Methods}

\section{Collection and maintenance of experimental animals}

The giant scallop, Placopecten magellanicus, population we studied is located at the mouth of Baie des Chaleurs near Percé, Québec, in eastern Canada’s Gulf of St. Lawrence, $\left(48^{\circ} 30^{\prime} \mathrm{N}, 65^{\circ} 15^{\prime} \mathrm{W}\right)$. As at this location, spawning events occur between mid-July and early September (Bonardelli et al. 1996), we sampled at three dates: July $5^{\text {th }}$ (before spawning events), September $6^{\text {th }}$ (during or just after or spawning) and October $18^{\text {th }} 2004$ (reproductive quiescence). At each sampling date, 9 scallops (shell height: $106.9 \pm 10.9 \mathrm{~mm}$ ) were collected by SCUBA diving at $30 \mathrm{~m}$ and water temperature was noted. Animals were transported on seawater ice in air to the research station of the Ministère de l'Agriculture, des Pêcheries et de l'Alimentation du Québec (MAPAQ) at Grande-Rivière (CAMGR), less than $50 \mathrm{~km}$ from the sampling site. Upon arrival at CAMGR, animals were tagged with Bee Tags $^{\mathrm{TM}}$ (labels were glued on the upper valve using a cyanoacrylate adhesive) and placed in three flow-through seawater tanks $(100 \mathrm{~L})$ kept at the water temperature measured during collection $\left(7.2^{\circ} \mathrm{C}\right.$ in July $5^{\text {th }}, 7.1^{\circ} \mathrm{C}$ in September $6^{\text {th }}$ and $6.3^{\circ} \mathrm{C}$ in October $18^{\text {th }}$ ) and held under natural photoperiod. Seawater was filtered $(1 \mu \mathrm{m})$ and UV-sterilized. Salinity varied between 28.2 and $29.1 \%$, as is encountered in the scallops' natural habitat. According to the stage of the experiment, the scallops were either starved or fed with phytoplankton cultures (see below).

At the end of each series of metabolic and behavioural analyses at CAMGR, scallops were flown live on frozen seawater (travel time less than 12 h) to Université Laval, Québec for analysis of mitochondrial performance, dissection and gonad sampling. After their arrival, scallops were placed in a $1000 \mathrm{~L}$ aquarium containing artificial seawater at $7.0 \pm 0.5{ }^{\circ} \mathrm{C}$. After $24 \mathrm{~h}$ of acclimation and during the subsequent 4-5 days, scallops were sampled to assess properties of muscle mitochondria, take gonad samples and measure tissue-wet masses. 
124 For each individual, part of the gonad was rinsed with filtered seawater and then fixed

125 in a 10\% Helly fixative (Shaw and Battle 1957). Tissues were dehydrated through an 126 ascending ethanol series and embedded in paraffin wax. Four $5 \mu \mathrm{m}$ thick sections were cut

127 through the entire piece of gonad and then stained with Ehrlich's haematoxylin and eosin 128 (H\&E). Reproductive condition was assessed from one field per section (four fields per 129 scallop) using stereological analysis. For females, the proportions of normal and atresic 130 oocytes per field (gamete volume fraction, GVF, and atresic volume fraction, AVF) were 131 estimated on histological slides examined at 400x magnification with an image capture kit

132 CoolSnap-Pro digital kit 4.1 (Pernet et al. 2003). Oocytes with atretic (abnormal shape or 133 colour) or lytic (denaturated) characteristics were considered to be in resorption (Lubet 1959).

134 For males and females, the gametogenic stage (indifferent, development, mature, spawning or 135 spent) of each individual was determined by microscopic observation of slides as described 136 by Lowe et al. 1982. We also estimated the gonadosomatic index (GSI: gonad wet mass/total 137 wet mass of soft tissues) as a quantitative criterion of reproductive stage. Individual scallops were placed in $60 \times 60 \times 12 \mathrm{~cm}$ trays containing $\sim 15 \mathrm{~L}$ of filtered

$141(1 \mu \mathrm{m})$ seawater at the habitat temperature and escape responses were measured following 142 Brokordt et al. (2000a) and Lafrance et al. (2003). After $2 \mathrm{~min}$ in the trays and when they 143 were ventilating normally, scallops were stimulated to swim and escape by touching them 144 with an arm of a sea star, Asterias vulgaris. The time before the first reaction of the scallop, 145 the maximal number of valve adductions (claps) in a series, the total number of claps before 146 exhaustion, and the escape time (total time until exhaustion minus the time before the 
147 scallop's first reaction) were noted. The observation was stopped if no claps occurred after 2

148 min of stimulation. After 30 min of recuperation (during which metabolic rate was measured),

149 each scallop underwent a second escape response test (again followed by 30 min of metabolic

150 rate measurement).

151 Sea stars were obtained from the same site as the scallops and were maintained in a

152 flow-through seawater tank $(100 \mathrm{~L})$ at temperatures similar to those of the scallop tanks. To

153 standardize their hunger level, sea stars were starved for $24 \mathrm{~h}$ before the experiments.

154

155

156

157

158

159

160

161

162

163

164

165

166

167

168

169

170

171

Metabolic rate measurements

$\mathrm{VO}_{2}$ min, or standard metabolic rate (SMR), estimates maintenance requirements of resting, unstressed organisms that are not digesting food and are at a stable temperature within their optimal range (Rolfe and Brown 1997). After being acclimated to maintenance conditions and starved for three days, the oxygen consumption of each scallop was measured at habitat temperature $\left(\approx 7^{\circ} \mathrm{C}\right)$ to estimate SMR. Animals were transferred individually into 1 L metabolic chambers that were maintained open for $60 \mathrm{~min}$ before starting measurements. Four chambers were used simultaneously, which allowed us to measure three animals and a blank with an empty shell. The oxygen consumption of individual animals was determined by sealing the chamber and measuring the reduction in percent dissolved $\mathrm{O}_{2}$ with a YSI (5331) polarographic electrode and analyzer. Seawater in the metabolic chamber was well mixed with a magnetic stirrer. The output signal was monitored continuously starting from $100 \%$ saturation and until at least a $20 \%$ decrease in saturation was reached. Immediately after measurements, scallops were re-introduced into the flow-through seawater tanks and fed a 1:1 mixture of Chaetoceros muelleri and Isochrysis galbana. The diet was supplied continuously, maintaining a concentration of $\sim 30$ cells. $\mu \mathrm{L}^{-1}$ in the tanks, allowing the scallops to feed to satiety for two days (Pernet et al. 2003; Pernet et al. 2005). 
173 the escape response tests. Scallops were transferred into metabolic chambers and oxygen

174 consumption was measured for $30 \mathrm{~min}$. Scallops were open and ventilating after a few

175 minutes in the chambers thus ensuring that animals were well into their aerobic recovery

176 phase. Therefore, their oxygen consumption most likely reflected the maximum $\mathrm{O}_{2}$

177 consumption rate (Tremblay et al. 2006). The escape response was then quantified a second

178 time, followed by a second determination of oxygen consumption rates. The higher of the two

179 oxygen uptake rates following fatigue was considered as the maximum metabolic rate

180 ( $\left.\mathrm{VO}_{2} \max \right)$ (Tremblay et al. 2006). Oxygen consumption $\left(\mathrm{ml} \mathrm{O}_{2} \cdot \mathrm{h}^{-1}\right)$ was expressed as the rate

181 expected for a standard animal (soft tissue wet mass of $50 \mathrm{~g}$ ) using the allometric correction,

$182 \mathrm{y}=\mathrm{aM}^{\mathrm{b}}$, where $\mathrm{y}$ is the oxygen consumption and $\mathrm{b}$ the scaling coefficient (Davies and Moyes

183 2007). We calculated a scaling coefficient of 0.8 using our data. We used wet instead of dry

184 mass as the denominator for oxygen uptake rates as the use of the muscle for subsequent

185 biochemical measurements prevented assessment of dry mass.

186

Mitochondrial isolation and measurement of substrate oxidation

Isolation procedures and measurements of substrate oxidation followed Guderley et al.

189 (1995) and Brokordt et al. (2000a). For mitochondrial isolation, all manipulations were

190 carried out on ice except the centrifugations, which were performed at $4^{\circ} \mathrm{C}$. Phasic muscles

191 were rinsed in $5 \mathrm{~mL}$ isolation medium and then minced. The minced muscle was then

192 homogenized in 8 volumes of ice-cold isolation buffer containing $480 \mathrm{mM}$ sucrose, $30 \mathrm{mM}$

193 HEPES, $230 \mathrm{mM} \mathrm{KCl}, 3 \mathrm{mM} \mathrm{Na} 2$ EDTA, $6 \mathrm{mM}$ EGTA, and $5 \mathrm{mM} \mathrm{MgCl}$, pH 7.0 at $25^{\circ} \mathrm{C}$. On

194 the day of the experiment, $0.1 \%$ fatty acid-free bovine serum albumin (BSA) was added. The

195 homogenate was centrifuged at $900 \mathrm{~g}$ for $10 \mathrm{~min}$ and the superficial lipid layer was removed.

196 The remaining supernatant was again centrifuged at $900 \mathrm{~g}$ for $10 \mathrm{~min}$. The resulting 
197 supernatant was considered free of unbroken cells or cell debris and was centrifuged at 9000g.

198 To optimize the purity of mitochondrial pellets and to remove $\mathrm{MgCl}_{2}$, the resulting pellet was 199 rinsed once by resuspension in isolation buffer free of $\mathrm{MgCl}_{2}$ and recentrifuged at $9000 \mathrm{~g}$. The 200 mitochondrial pellet was re-suspended in a volume of reaction buffer corresponding to one201 tenth of the mass of muscle used.

202 Mitochondrial oxygen uptake was measured polarographically using a water-jacketed $203 \mathrm{O}_{2}$ monitoring system (Qubit System, Kingston, Ontario, Canada). Temperature was 204 maintained at $5^{\circ} \mathrm{C}$ by a circulating refrigerated water bath. For each assay, around $1 \mathrm{mg}$ of 205 mitochondrial protein $(\sim 100 \mu \mathrm{L}$ mitochondrial preparation) was added to $1 \mathrm{~mL}$ assay medium 206 containing $480 \mathrm{mM}$ sucrose, $70 \mathrm{mM}$ HEPES, $100 \mathrm{mM} \mathrm{KCl}, 10 \mathrm{mM} \mathrm{KH} \mathrm{PO}_{4}, 50 \mathrm{mM}$ taurine 207 and $\beta$-alanine, $\mathrm{pH}$ 7.0. On the day of the experiment, $0.5 \%$ BSA was added to the assay 208 medium (Guderley et al. 1995). To obtain maximal rates of respiration (state 3), glutamate 209 was added to a final concentration of $24 \mathrm{mmol} \cdot \mathrm{L}^{-1}$ and ADP to a final concentration of 0.4 210 mmol. $\mathrm{L}^{-1}$. The ADP/O ratio was measured according to Chance and Williams (1956). Only 211 mitochondrial preparations with respiratory control ratios (RCR; state 3 / state 4, when ADP 212 was depleted) $\geq 3$ were used. Preliminary experiments established that glutamate was 213 oxidized at higher rates than pyruvate or succinate.

\section{Cytochrome C oxidase activity} $\mathrm{CCO}$ activity was measured at $5^{\circ} \mathrm{C}$ and $15^{\circ} \mathrm{C}$ according to Kraffe et al. (2007). Fresh 217 mitochondrial suspensions were diluted in phosphate buffer without Triton-X (45 mmol.L ${ }^{-1}$ $218 \mathrm{KH}_{2} \mathrm{PO}_{4}$ and 30 mmol.L $\mathrm{L}^{-1} \mathrm{~K}_{2} \mathrm{HPO}_{4}, \mathrm{pH}$ 6.8). We used an initial cytochrome $\mathrm{C}$ concentration of $219100 \mu \mathrm{mol.L} \mathrm{L}^{-1}$. All assays were run in triplicate using fresh mitochondrial preparations. 220 Activities were calculated using an extinction coefficient of $19.1 \mathrm{mmol} \cdot \mathrm{L}^{-1} . \mathrm{cm}^{-1}$ (first order 221 reaction). 

samples were read against samples oxidized with 5 mmol. $\mathrm{L}^{-1}$ ferricyanide. The concentration of adenine nucleotide translocase (ANT) in mitochondrial suspensions was measured by titration with its non-competitive irreversible inhibitor, carboxyatractyloside (CAT) (Guderley

et al. 2005). The quantity of ANT in mitochondrial suspensions corresponded to the amount of CAT needed for inhibition. The protein concentration in mitochondrial suspensions was determined by the bicinchoninic acid method (Smith et al. 1985) using BSA.

Membrane lipid analysis

The membrane lipids of mitochondrial suspensions were extracted according to Folch et al. (1957) as modified for mitochondrial preparations (Kraffe et al. 2007). Separation of polar and neutral lipids on silica gel micro-columns, separation of membrane lipid classes, FA and sterol analyses, and calculation of amounts of phospholipid classes followed Kraffe et al. 240 (2007).

Separation of polar lipids on silica gel micro-columns

243 x 5 mm i.d., packed with Kieselgel 60 (70-230 mesh, Merck) previously heated at $450^{\circ} \mathrm{C}$ and

244 deactivated with $6 \mathrm{wt} \% \mathrm{H}_{2} \mathrm{O}$ (Marty et al. 1992). Neutral lipids were eluted with $10 \mathrm{~mL}$ of $245 \mathrm{CHCl}_{3} / \mathrm{MeOH}(98: 2, \mathrm{vol} / \mathrm{vol})$ and stored at $-20^{\circ} \mathrm{C}$ for later sterols analysis. The polar lipid 246 fraction was recovered with $20 \mathrm{~mL}$ of $\mathrm{MeOH}$ and stored at $-20^{\circ} \mathrm{C}$ for later phospholipid class 
separation by high performance liquid chromatography (HPLC) and FA composition analysis

248 by gas chromatography (GC).

\section{Cholesterol analysis}

Free sterols (membrane components) and esterified sterols (sterol reservoir and

reserves) from the neutral lipid fraction were not previously separated since sterols are mostly

in the free form in scallop muscle (Napolitano and Ackman 1992; Palacios et al. 2007). An

aliquot of the neutral lipid fraction was transesterified with methoxide (MeONa) for 90 min at

ambient temperature (Soudant et al. 1996). The sterols thus released were extracted in hexane

and injected directly into GC. Sterols were analyzed in a Chrompak 9002 gas chromatograph

equipped with a RTX65 (65\% diphenyl, 35\% dimethylpolysiloxane) fused silica capillary

column (50 m x $0.32 \mathrm{~mm}, 0.2 \mathrm{pm}$ film thickness) using an on-column injection system and

hydrogen as carrier gas, with a thermal gradient from 60 to $280^{\circ} \mathrm{C}$. Quantification of sterols

was achieved by adding a known quantity of cholestane to samples.

Separation of membrane lipid classes and FA analysis

Separation of phospholipid classes and subclasses used two successive HPLC

separations with two different mobile phases. This method allowed the separate analysis of

plasmalogen (1-alkenyl-2-acyl-) and diacyl subclasses of phosphatidylethanolamine (PE),

phosphatidylcholine (PC) and phosphatidylserine (PS) in bivalves along with cardiolipin

(CL), phosphatidylinositol (PI), and natural lysophosphatidylcholine (LysoPC) (Kraffe et al.

267 for FA composition. Fatty acid methyl esters (FAME) obtained were identified and quantified

268 using both polar (CPWAX $52 \mathrm{CB}-50 \mathrm{~m}$ x $0.25 \mathrm{~mm}$ i.d.; $0.2 \mu \mathrm{m}$ thickness) and non-polar

269 (CP-Sil 8 CB $-25 \mathrm{~m}$ x $0.25 \mathrm{~mm}$ i.d.; 0.25 $\mu \mathrm{m}$ thickness) capillary columns and C23:0 FA as an

270 internal standard. FA were expressed as the molar percentage of the total FA content of each

271 class or subclass. For plasmalogen subclasses, the total percentage was adjusted to $50 \%$ to 
take into account the absence of alkenyl chains of the $s n-1$ position hydrolyzed by the acid mobile phase.

\section{Calculation of amounts of phospholipid classes}

The quantities of each phospholipids class and subclass of were determined from their respective FA spectrum obtained by GC. To obtain the molar content of each analyzed fraction, a correction factor was applied to their respective total FA molar contents: $\mathrm{x} 1$ for plasmalogen fractions and for the natural lysoPC fraction; $\mathrm{x} 1 / 2$ for PI and the diacyl fractions of PE, PC and PS, and x1/4 for the CL fraction.

\section{Statistical analysis}

Statistical comparisons were carried out with StatGraphics Plus 5.1 (Sigma Plus Inc., Toulouse, France). Initial two-factor analysis of variance (ANOVA) (reproductive stage and sex as factors) established that sex was not a significant factor for the measured parameters, thus values for males and females were pooled. None of the variables we measured showed any significant tank effect or interaction between tank and reproductive state. One-way ANOVA followed by a posteriori Bonferoni multiple comparisons was used for analysis of the effect of reproductive stage on behaviour, metabolic measurements and mitochondrial characteristics. Differences were considered significant when $\mathrm{P}<0.05$.

For lipid compositions, expressed as mol\%, two-way factorial multiple analysis of variance (MANOVA) using SPSS 13.0 (Lead Technologies, Chicago, Illinois, USA) was applied with reproductive stage as the factor. Data were $\log +1$ or $1 /$ sqrt $(\mathrm{x})$ transformed before the analysis. Where differences were detected, least-square means multiple comparison tests were used to determine which means were significantly different. Residuals were screened for normality using expected normal probability plots and homogeneity of variance was assessed with Levene's Test. 


\section{Results}

Reproductive status

The gamete volume fraction (GVF) and gonadosomatic index (GSI) both showed a significant effect of date (Figure $1, P<0.001$ ). The highest values were observed on July $5^{\text {th }}$ and represented the mature (or ripe) gametogenic stage; lower values were observed on September $6^{\text {th }}$ and October 18 th. Maturation stage as determined by microscopy indicated that all male (2) and female (7) scallops in July had mature gonads (pre-spawned). Although GVF and GSI did not discriminate between scallops in the September and October samples, maturation stages did. In September, all female gonads (3) were spent while 4 of the 6 males analyzed were virtually spent and 2 were spent. In October, all male gonads (3) were spent, 1 of the 5 female gonads was spent and 4 showed small primary oocytes. Thus, we identified scallops sampled in early September as spawned and those in October as reproductive quiescent.

\section{Escape response behaviour}

All behavioural responses except for the maximum number of claps in a series, changed with reproductive stage (Figure 2). Specifically, reproductive-quiescent scallops took more time to respond to the predator both for their initial test $(\mathrm{P}<0.001)$ and after $30 \mathrm{~min}$ of recuperation $(\mathrm{P}=0.03)$ (Figure 2a). Spawned scallops made fewer claps before exhaustion than did pre-spawned and reproductive-quiescent scallops $(\mathrm{P}=0.03)$ (Figure 2c). Total escape time was shorter for spawned scallops during their initial response and after $30 \mathrm{~min}$ of recuperation $(\mathrm{P}<0.001)$ (Figure $2 \mathrm{~d})$. Spawned scallops tended to have a lower capacity for recovery, only performing $56 \%$ of their initial claps after recovery whereas scallops in the other reproductive stages responded with $68-75 \%$ of their initial claps (Table 1). After 30 min of recuperation, the escape responses of pre-spawned and reproductive-quiescent scallops 

323 initial escape duration $(\mathrm{P}=0.02)$ (Table 1).

324

325

\section{Aerobic power budget} spawned scallops (Figure 4). changed little between reproductive stages.

lasted $82-85 \%$ of their initial duration while spawned animals only responded for $53 \%$ of their

Metabolic rates after exhaustion $\left(\mathrm{VO}_{2} \mathrm{max}\right)$ did not vary significantly with reproductive state, but $\mathrm{VO}_{2}$ min did, with higher values of oxygen consumption in spawned scallops than at the other stages $(\mathrm{P}<0.001)$ (Figure 3). Whole animal metabolic rates and allometrically corrected rates showed the same trends between reproductive stages. $\mathrm{VO}_{2} \mathrm{~min} / \mathrm{VO}_{2} \max$ ratios, indicating the proportion of oxygen consumption needed for maintenance, showed values of 34 and $41 \%$ in pre-spawned and reproductive-quiescent animals and significantly higher values in spawned scallops (59\%, P=0.005) (Figure 3). Aerobic scope, i.e. the difference between maximum and standard $\mathrm{VO}_{2}$, tended to be lowest in

Oxidative capacities and composition of muscle mitochondria Maximal rates of glutamate oxidation (State 3) (nmol O.min ${ }^{-1} \cdot \mathrm{mg}^{-1}$ mitochondrial protein) did not change with reproductive stage (Table 2). State 4 rates (nmol O. $\min ^{-1} \cdot \mathrm{mg}^{-1}$ mitochondrial protein) and the phosphorylation capacity of mitochondria, expressed as the molar ratio between added ADP and consumed oxygen (ADP/O), also

The denominator typically used to standardize mitochondrial rates is the protein content in the mitochondrial preparation. To evaluate rates of oxygen uptake relative to parameters that are exclusively located in mitochondrial membranes, we used the concentrations of ANT and cytochromes $\mathrm{A}, \mathrm{B}$ and $\mathrm{C}_{1}$ as denominators. Cytochrome levels (expressed relative to the $\mathrm{mg}$ of proteins in the mitochondrial preparations) did not change 
significantly between reproductive stages except that cytochrome B was higher in spawned

348 and reproductive-quiescent scallops compared to pre-spawned animals ( $\mathrm{P}=0.02)$ (Table 3).

349 The protein-specific levels of ANT exceeded those of the cytochromes and were significantly

350 higher $(\mathrm{P}<0.001)$ in reproductive-quiescent scallops compared to pre-spawned and spawned

351 scallops. Modifications in the maximal rates of glutamate respiration were more apparent

352 when mitochondrial membrane proteins were used as the denominator. When State 3 rates

353 were expressed over cytochrome B, they were higher in pre-spawned scallops than in the

354 other reproductive states $(\mathrm{P}=0.07)$. When expressed per nmol of ANT, mitochondrial rates

355 were significantly lower in reproductive-quiescent scallops than in the other reproductive 356 stages $(\mathrm{P}=0.02)$ (Figure 5).

357

Cytochrome C oxidase activity

$\mathrm{CCO}$ activity in mitochondrial suspensions was nearly two-fold higher in reproductive-quiescent animals than in the other reproductive stages at both 5 and $15^{\circ} \mathrm{C}$ $(\mathrm{P}<0.001)$ (Figure 6). The same pattern was found when CCO activity was expressed over cytochrome A levels, except that spawned scallops showed an intermediate catalytic capacity. The $\mathrm{Q}_{10}$ for CCO remained between 1.7 and 1.85 for the different reproductive stages. Whereas all of the measured $\mathrm{CCO}$ activity was used by mitochondria oxidizing glutamate (State 3/CCO activity expressed in $\mathrm{mU}$ ) in pre-spawned and spawned scallops $(100.9 \% \pm 10.3$ and $109.9 \% \pm 3.5$, respectively), the proportion decreased to $71.8 \% \pm 6.4$ in reproductivequiescent scallops $(\mathrm{P}=0.006)$.

\section{Composition of mitochondrial membrane lipids with reproductive stage}

The HPLC method used in the present study allowed the separate analysis of plasmalogen (1-alkenyl-2-acyl-) and diacyl subclasses of phosphatidylethanolamine (PE), 
372 phosphatidylcholine (PC) and phosphatidylserine (PS) found in scallops, along with 373 phosphatidylinositol (PI), cardiolipin (CL), and natural lysophosphatidylcholine (LysoPC).

374 The diacyl forms of phosphatidylcholine (diacylPC), phosphatidylethanolamine (diacylPE), 375 and phosphatidylserine (diacylPS), as well as phosphatidylinositol (PI) and cardiolipin (CL) 376 were the predominant phospholipid classes in the mitochondrial fraction from scallop muscle 377 (Figure 7). Plasmalogen forms were found in PE (PlsmPE) while they were only present in 378 trace amounts in PC and PS. LysoPC was also always found in trace amounts.

379 The relative levels $(\mathrm{mol} \%)$ and content $\left(\mathrm{nmol} . \mathrm{mg}^{-1}\right.$ protein) of glycerophospholipids 380 (total, classes and subclasses) remained stable between the three reproductive stages (Figure 7 381 and Table 4). Total sterol content did not change significantly with reproductive stage and 382 constituted one third of total lipids (glycerophospholipids + sterols) in the mitochondrial 383 preparations. Sterols were principally composed of cholesterol (28\%), 24-

384 methylenecholesterol (18\%), brassicasterol (15\%), 22-dehydrocholesterol (9\%), 385 norcholesterol (5\%) and $\beta$-sitosterol (5\%) and the relative levels did not change between the 386 reproductive stages (data not shown).

Fatty acyl chain composition of membrane phospholipid classes and subclasses between reproductive stages

390 The total phospholipids were dominated by 16:0 for the saturated fatty acids (SFA) 391 and by $20: 5 n-3$ and 22:6n-3 as the main unsaturated FA. The other major FA were 18:0 and 392 18:1n-7. The FA composition of total phospholipids was remarkably stable between the three 393 reproductive stages (Table 5). Few modifications were detected in the FA compositions of 394 the specific phospholipid classes and subclasses of mitochondrial fractions (data not shown). 395 A major exception was the FA composition of the minor phospholipid class CL (Figure 8). 396 The predominant FA, 22:6n-3, was higher in reproductive-quiescent scallops than in pre- 
397 spawned scallops, $(\mathrm{P}=0.02)$ whereas $20: 5 \mathrm{n}-3$ represented $10 \%$ of the FA in pre-spawned and 398 spawned scallops and decreased threefold in reproductive-quiescent animals $(\mathrm{P}<0.001)$. 399 Levels of 18:0 were also lower in reproductive-quiescent scallops compared to pre-spawned 400 scallops $(\mathrm{P}=0.02)$. The decreases in 20:5n-3 and 18:0 accounted for the increase of 22:6n-3. 401 402 
402

403

404

405

406

407

408

409

410

411

412

413

414

415

416

417

418

419

420

421

422

423

424

425

426

\section{Discussion}

\section{Metabolism and behavioural responses}

Standard metabolic rates (SMR) of $P$. magellanicus varied with reproductive stage. In numerous bivalves, oxygen uptake varies seasonally in relation to ambient temperature and food availability, both of which are linked with the energy demands of gametogenesis (MacDonald and Thompson 1986; Shumway et al. 1988; Delgado and Pérez Camachao 2007 Tran et al. 2008). The influence of temperature on SMR found for scallops $P$. magellanicus in our study cannot explain the differences in SMR since temperature varied little between sampling dates and thus, during metabolic rate measurements. Standard metabolic rates were higher in spawned scallops, than in pre-spawned or reproductive-quiescent scallops. The lower SMR in pre-spawned scallops is not expected for bivalves during gametogenesis (Shumway et al. 1988; Delgado and Pérez Camachao 2007). Nevertheless, $\mathrm{O}_{2}$-consumption in the oyster $C$. gigas was shown to be lower in mature pre-spawned animals than after they had spawned (Soletchnik et al. 1997, Tran et al. 2008). In our study, the increase in SMR after spawning remains to be explained. The scallops sampled in July were likely close to spawning and had probably completed gametogenesis, as reflected by oocytes maturity. At Percé, in the Baie des Chaleurs, spawning takes place 2 or 3 months after the spring phytoplankton bloom in May/June (Bonardelli et al. 1996). Once the gametes are mature, scallops may have lower energy demands than during periods of gonad development, which require high rates of food ingestion and mobilization of energy reserves. Tran et al. (2008) suggested that cardiac output could be limited by mechanical pressure on the ventricle, since the large gonadal volume in pre-spawning bivalves could limit blood flow and oxygen consumption. In spawned scallops, the increased SMR may reflect enhanced energetic needs during and after spawning, including the needs for tissue restoration. 
While we observed a marked increase in standard metabolism of spawned scallops, no 428 significant changes in maximum metabolic rate with reproductive stage were found. 429 Consequently, $\mathrm{VO}_{2} \mathrm{~min} / \mathrm{VO}_{2} \max$ ratios (proportion of $\mathrm{VO}_{2}$ required for maintenance 430 requirements) differed between reproductive stages, indicating a greater maintenance demand 431 in spawned scallops. Similarly, aerobic scope (i.e., the difference between maximum and 432 standard $\mathrm{VO}_{2}$ ) tended to be lower in spawned than in pre-spawned and reproductive-quiescent 433 scallops (Figure 4). The weakness of spawned scallops in their initial escape test as well as in 434 the capacity for recuperation may reflect this aerobic power budget. Indeed, spawned scallops 435 had a shortened total escape time and made fewer claps before exhaustion than pre-spawned 436 and reproductive-quiescent scallops. Even with this weaker initial escape response, spawned 437 scallops recovered a lower proportion of their initial status after a 30 min rest. Given the 438 patterns of metabolic support for swimming, the reduced initial escape response in spawned 439 scallops could reflect reduced arginine kinase activity or arginine phosphate levels in the 440 adductor muscle of spawned animals, such as seen in Chlamys islandica (Brokordt et al. 441 2000a) and Euvola ziczac (Brokordt et al. 2000b). In Chlamys islandica, Euvola ziczac and 442 Argopecten purpuratus, gametogenesis and spawning also reduce recuperation from 443 exhausting exercise (Brokordt et al. 2000a; Brokordt et al. 2000b; Brokordt and Guderley 444 2004). Since complete recuperation of phosphoarginine levels after exhausting exercise 445 requires aerobic metabolism (Livingstone et al. 1981), the increased maintenance 446 requirements of spawned scallops would slow their metabolic recuperation.

447 In contrast to responses observed for C. islandica and E. ziczac, but similar to results 448 for Argopecten purpuratus (Brokordt et al. 2006), escape response behaviours measured at 449 different points in the reproductive cycle varied both in initial tests and during repeat escape 450 tests. In P.magellanicus as in A. purpuratus, various parameters, including the time to first 451 respond to the sea star, the number of initial claps and the initial clapping time changed with 
452 reproductive investment. In A. purpuratus, the impact of reproductive investment differed 453 between domesticated and wild scallops (Brokordt et al. 2006). Both in P. magellanicus and 454 A. purpuratus, the most marked changes were in the time to first respond to the predator. It is 455 unlikely that this parameter is linked with the changed aerobic power budget. However, the 456 decreased escape performance in spawned scallops could have a metabolic basis. We suggest 457 that, for the various species of scallops for which an impact of reproductive investment upon 458 escape response performance has been noted, limitations in the aerobic power budget may be 459 a central mechanism affecting performance.

\section{Mitochondrial rates of glutamate oxidation and CCO activity}

Brokordt et al. 2000a; Brokordt and Guderley 2004). This lack of change in maximal capacities of muscle mitochondria for glutamate parallels the lack of change of organismal maximal aerobic capacities $\left(\mathrm{VO}_{2} \mathrm{max}\right)$. The limited changes in the capacities for glutamate oxidation of muscle mitochondria (per mg protein) do not preclude modifications in the capacity for oxidation of other substrates, such as pyruvate. Indeed, during gonadal maturation and immediately after spawning, Chlamys islandica have lower mitochondrial

470 capacities for pyruvate oxidation (Brokordt et al. 2000a). Pyruvate being the principal 471 substrate to be oxidized after muscular activity, this reduced capacity for pyruvate oxidation 472 was suggested to slow the aerobic recovery of scallops from exhausting escape responses 473 (Guderley et al. 1995; Brokordt et al. 2000a).

474 Numerous enzymatic complexes participate in oxidative phosphorylation, with 475 complex IV (CCO) having significant control over mitochondrial respiration rates (Groen et 476 al. 1982; Blier and Lemieux 2001). In scallop muscle mitochondria, CCO activity did not 
477 follow the same patterns as rates of glutamate oxidation expressed over proteins, cytochromes

478 or ANT. This suggests that in scallop muscle, maximal rates of glutamate respiration (state 3

479 rates) are not dictated, solely or in part, by changes in CCO capacity. The calculated

480 proportion of maximal CCO capacity used by the mitochondria oxidizing glutamate (State

481 3/CCO activity expressed in $\mathrm{mU}$ ) was lower in reproductive-quiescent scallops than in pre- or

482 spawned scallops. These calculated values are high compared to those for fish red muscle

483 (Blier and Lemieux 2001; Kraffe et al. 2007) and may be due to differing assay conditions.

Membrane lipid composition

Proportions of phospholipid classes and subclasses as well as those of sterols did not

change with reproductive state. Few modifications were apparent for the FA composition of

total phospholipids or of specific phospholipid classes and subclasses. However, among the

isolated classes, marked differences were found in the FA composition of CL. This minor

490 phospholipid class, predominantly constituted of 22:6n-3 in scallops (Kraffe et al. 2002),

showed fairly high proportions (10 mol\% of the total FA in CL) of 20:5n-3 in pre-spawned

and spawned scallops whereas this FA in reproductive-quiescent scallops was three fold less

concentrated and 22:6n-3 was present at a significantly higher level. Interestingly, the

decrease in 20:5n-3 (and the increase in 22:6n-3) in CL coincided with the increase in CCO

495 activity.

496 Control of membrane-bound protein complexes in mitochondria (CCO, cytochrome $497 b c_{1}$ complex, ADP-ATP translocase) is exerted partly at the level of CL (Schlame et al. 2000;

498 Paradies et al. 2002; Schlame and Ren 2006), with changes in the FA composition of CL

499 influencing, at least in part, the activity of these membrane complexes. In particular, 500 alterations in the CL acyl composition are suggested to modulate the CCO activity in 501 mammals (Yamaoka et al. 1988; Robinson et al. 1990; Berger et al. 1993; Watkins et al. 
502

503

504

505

506

507

508

509

510

511

512

513

514

515

516

517

518

519

520

521

522

523

524

525

526

1998) as well as in fish (Wodtke 1981; Kraffe et al. 2007). We found that changes in CCO activity in scallop muscle mitochondria with reproductive stage paralleled FA modifications of this annular phospholipid. We propose that the increase of CCO activity in reproductivequiescent scallops is due, at least in part, to decreased levels of 20:5n-3 in CL concomitant with increases in 22:6n3.

\section{Standard metabolic rate and muscle mitochondrial properties}

Basal mitochondrial proton conductance (or proton leak) may account for $20-25 \%$ of SMR (Rolfe et al. 1999). Although quantitative estimates of the contribution of mitochondrial proton leak to standard metabolic rate are not available for scallops, the mitochondrial carrier protein, ANT, and the FA composition of inner-membrane phospholipids can explain much of the variation in basal proton conductance in many animals (Brand et al. 2005; Hulbert and Else 2005). If ANT were an important determinant of basal proton conductance in scallop muscle mitochondria, then mitochondria in reproductive quiescent scallops, with their higher ANT contents, would have a higher proton leak. However, the lack of change of state 4 rates with reproductive stage suggests that proton leak does not increase with ANT levels. Furthermore, the minor changes in the FA composition of total phospholipids in muscle mitochondria suggest that they would contribute little to shifts in proton conductance between reproductive stages. Thus, the increased SMR in spawned scallops is more likely associated with other energetic needs or mechanical routes.

\section{Conclusion}

This study examined mechanisms that could explain changes in escape response performance of giant scallop, Placopecten magellanicus, with reproductive status. We found a rise in standard metabolic rate without significant changes in maximum metabolic rate in 
527

528

529

530

531

532

533

534

535

536

537

538

539

540

541

542

543

544

545

546

547

spawned scallops, suggesting that increased maintenance requirements and decreased aerobic scope limit their capacity to escape and to recover from exhaustion. While examining muscle mitochondrial properties, we found that glutamate oxidation capacity did not change with reproductive status, although CCO did. Even though our examination at these multiple levels did not seem to draw a single causal chain between the molecular and organismal levels, links were apparent between some levels of organization. The stability of maximal organismal $\mathrm{VO}_{2}$ paralleled the lack of change of maximal capacities for glutamate oxidation by phasic muscle mitochondria. This suggests a possible role of muscle mitochondria in setting organismal $\mathrm{VO}_{2} \mathrm{max}$. $\mathrm{CCO}$ activity modification was associated with changes in the FA composition of CL. In keeping with the regulatory role of $\mathrm{CL}$ for major complexes in oxidative phosphorylation, the marked changes in 20:5n-3 and 22:6n-3 of CL suggest that the specific FA composition of CL may modify CCO activity in scallop muscle.

\section{Acknowledgements}

This research was supported by a grant from NSERC to HG. EK received post-doctoral support from the Reseau Aquacole du Québec and from the Université de Bretagne Occidentale. The direction of innovation and technology of the Ministère de l'Agriculture, des Pêcheries et de l'Alimentation du Québec (MAPAQ) allowed accessibility and metabolic measurements at CAMGR. 


\section{References}

548

549

550

551

552

553

554

555

556

557

558

559

560

561

562

563

564

565

566

567

568

569

570

571

572

573

574

575

576

577

578

579

Bailey DM, Peck LS, Bock C, Pörtner HO (2003) High-energy phosphate metabolism during exercise and recovery in temperate and Antarctic scallops: an in vivo ${ }^{31} \mathrm{P}-\mathrm{NMR}$ study. Physiol Biochem Zool 76: 622-633.

Barber BJ, Blake NJ (1981) Energy storage and utilization in relation to gametogenesis in Argopecten irradians concentricus (Say). J Exp Mar Biol Ecol 52: 121-134.

Barber BJ, Blake NJ (1985) Substrate catabolism related to reproduction in the bay scallop Argopecten irradians concentricus, as determined by $\mathrm{O} / \mathrm{N}$ and RQ physiological indexes. Mar. Biol. 87: 13-18.

Barber BJ, Blake NJ (1991) Reproductive physiology. In: Shumway SE (ed) Scallops: biology, ecology and aquaculture. Elsevier, Amsterdam, pp 377-428.

Berger A, German JB, Gershwin ME (1993) Biochemistry of CL: sensitivity to dietary fatty acids. In: Kissela JE (ed) Advances in food and nutrition research, vol 37. Academic Press, San Diego, pp 259-338.

Blier PU, Lemieux H (2001) The impact of the thermal sensitivity of cytochrome $c$ oxidase on the respiration rate of Arctic charr red muscle mitochondria. J Comp Physiol B 171: 246-253.

Boadas MA, Nusetti OA, Mundarain F, Lodeiros C, Guderley H (1997) Seasonal variation in the properties of muscle mitochondria fro the tropical scallop Euvola (Pecten) ziczac. Mar Biol 128: 247-255.

Bonardelli JC, Himmelman JH, Drinkwater K (1996) Relation of spawning of the giant scallop, Placopecten magellanicus, to temperature fluctuations during downwelling events. Mar Biol 124: 637-649.

Brand MD, Pakay JL, Ocloo A, Kokoszka J, Wallace DC, Brookes PS, Cornwall EJ (2005) The basal proton conductance of mitochondria depends on adenine nucleotide translocase content. Biochem J 392: 353-362.

Brokordt KB, Himmelman JH, Guderley HE (2000a) Effect of reproduction on escape responses and muscle metabolic capacities in the scallop Chlamys islandica Müller 1776. J Exp Mar Biol Ecol 251: 205-225.

Brokordt KB, Himmelman JH, Nusetti OA, Guderley HE (2000b) Reproductive investment reduces recuperation from exhaustive escape activity in the tropical scallop Euvola zizac. Mar Biol 137: 857-865. 
580 Brokordt KB, Guderley H (2004) Energetic requirements during gonad maturation and

581

582

583

584

585

586

587

588

589

590

591

592

593

594

595

596

597

598

599

600

601

602

603

604

605

606

607

608

609

610

611 spawning in scallops: sex differences in Chlamys islandica (Müller 1776). J Shell Res 23: $25-32$.

Brokordt KB, Fernandez M, Gaymer C (2006) Domestication reduces the capacity to escape from predators. J. Exp. Mar. Biol. Ecol. 329: 11-19.

Chance B, Williams GR (1956) The respiratory chain and oxidative phosphorylation. Adv Enzymol 17: 65-134.

Chih PC, Ellington WS (1986) Control of glycolysis during contractile activity in the phasic adductor muscle of the bay scallop, Argopecten irradians concentricus: identification of potential sites of regulation and a consideration of the control of octopine dehydrogenase activity. Physiol Zool 59: 563-573.

Clandinin MT, Field CJ, Hargraves K, Morson L, Zsigmond E (1985) Role of diet fat in subcellular structure and function. Can J Physiol Pharmacol 63: 546-556.

Davies R, Moyes CD (2007) Allometric scaling in centrarchid fish: origins of intra- and interspecific variation in oxidative and glycolytic enzyme levels in muscle. J Exp Biol 210: 3798-3804.

de Zwaan A, Thompson RJ, Livingstone DR (1980) Physiological and biochemical aspects of valve snap and valve closure responses in the giant scallop Placopecten magellanicus. II. Biochemistry. J Comp Physiol 137: 105-114.

Delgado M, Pérez Camachao A (2007) Influence of temperature on gonadal development of Ruditapes philippinarum (Adams and Reeve, 1850) with special reference to ingested food and energy balance. Aquaculture 264: 398-407.

Folch J, Lees M, Sloane-Stanley GH (1957) A simple method for the isolation and purification of total lipides from animal tissues. J Biol Chem 226: 497-509.

Groen AK, Wanders RJA, Westerhoff HV, Van der Meer R, Tager JM (1982) Quantification of the contribution of various steps to the control of mitochondrial respiration. J Biol Chem 257: 2754-2757.

Guderley HE, Rojas FM, Nusetti OA (1995) Metabolic specialization of mitochondria from scallop phasic muscles. Mar Biol 122: 409-416.

Guderley H, Turner ND, Else PL, Hulbert AJ (2005) Why are some mitochondria more powerful than others: Insights from comparisons of muscle mitochondria from three terrestrial vertebrates. Comp Biochem Physiol B 142: 172-180. 
612 Hazel JR (1972a) The effect of temperature acclimation upon succinic dehydrogenase activity 613 from the epaxial muscle of the common goldfish (Carassius auratus L.) - I. Properties 614 of the enzyme and the effect of lipid extraction. Comp Biochem Phys 43B: 837-861.

615 Hazel JR (1972b) The effect of temperature acclimation upon succinic dehydrogenase activity 616 from the epaxial muscle of the common goldfish (Carassius auratus L.) - II. Lipid 617 reactivation of the soluble enzyme. Comp Biochem Phys 43B: 863-882.

618 Hulbert AJ, Else PL (2005) Membranes and the setting of energy demand. J Exp Biol 208: $619 \quad 1593-1599$.

620 Kraffe E, Soudant P, Marty Y, Kervarec N, Jehan P (2002) Evidence of a 621 tetradocosahexaenoic cardiolipin in some marine bivalves. Lipids 37: 507-514.

622 Kraffe E, Soudant P, Marty Y (2004) Fatty acids of serine, ethanolamine and choline 623 plasmalogens in some marine bivalves. Lipids 39: 59-66.

624 Kraffe E, Marty Y, Guderley H (2007) Changes in mitochondrial oxidative capacities during 625 thermal acclimation of rainbow trout Oncorhynchus mykiss: roles of membrane 626 proteins, phospholipids and their fatty acid compositions. J Exp Biol 210: 149-165.

627 Lafrance M, Cliche G, Haugum G, Guderley H (2003) Comparison of cultured and wild sea 628 scallops, Placopecten magellanicus (Gmelin, 1791), using behavioral responses, 629 morphometric and biochemical indices. Mar Ecol Prog Ser 250: 183-195.

630 Livingstone DR, de Zwaan A, Thompson RJ (1981) Aerobic metabolism, octopine production 631 and phosphoarginine as sources of energy in the phasic and catch adductor muscles of the giant scallop Placopecten magellanicus during swimming and the subsequent recovery period. Comp Biochem Phys 70B: 35-44.

Lowe DM, Moore MN, Bayne BL (1982) Aspects of gametogenesis in the marine mussel Mytilus edulis L. Mar Biol Ass U.K. 62: 133-145.

Lubet P (1959) Recherches sur le cycle sexuel et l'émission des gamètes chez les mytilidés et les pectinidés. Rev Trav Inst Pêches Marit 23: 389-548.

MacDonald BA, Thompson RJ (1986) Influence of temperature and food availability on the ecological energetics of the giant scallop Placopecten magellanicus. Mar Biol 93:37-

641 Marty Y, Delaunay F, Moal J, Samain JF (1992) Changes in the fatty acid composition of the 642 scallop Pecten maximus (L.) during larval development. J. Exp. Mar. Biol. Ecol. 163: 643 221-234 
644 Napolitano GE, Ackman RG (1992) Anatomical distributions and temporal variations of lipid 645 classes in sea scallops Placopecten magellanicus (Gmelin) from Georges Bank (Nova 646 Scotia). Comp Biochem Phys 103: 645-650.

647 Palacios E, Racotta IS, Arjona O, Marty Y, Le Coz JR, Moal J, Samain JF (2007) Lipid 648 composition of the pacific lion-paw scallop, Nodipecten subnodosus, in relation to 649 gametogenesis 2. Lipid classes and sterols. Aquaculture 266: 266-273.

650 Paradies G, Petrosillo G, Pistolese M, Ruggiero FM (2002) Reactive oxygen species affect 651 mitochondrial electron transport complex I activity through oxidative cardiolipin 652 damage. Gene 286: 135-141.

653 Pernet F, Tremblay R, Bourget E (2003) Biochemical indicator of sea scallop (Placopecten 654 magellanicus) quality based on lipid class composition. Part I: Broodstock 655 conditionning and young larvae performance. J Shell Res 22: 365-376.

656 Pernet F, Bricelj VM, Parrish CC (2005) Effect of varying dietary levels of w6 657 polyunsaturated fatty acids during the early ontogeny of the sea scallop, Placopecten 658 magellanicus. J Exp Mar Biol Ecol 327: 115-133.

659 Robinson NC, Zborowski J, Talbert LH (1990) Cardiolipin-depleted bovine heart cytochrome $660 \quad c$ oxidase: Binding stoichiometry and affinity for cardiolipin derivatives. Biochemistry $661 \quad 29: 8962-8969$.

662 Rolfe DFS, Brown GC (1997) Cellular energy utilization and molecular origin of standard 663 metabolic rate in mammals. Physiol Rev 77: 731-758.

664 Rolfe DFS, Newman JM, Buckingam JA, Clark MG, Brand MD (1999) Contribution of 665 mitochondrial proton leak to respiration rate in working skeletal muscle and liver and 666 to SMR. Am J Physiol 276: C692-C699.

667 Schlame M, Rua D, Greenberg ML (2000) The biosynthesis and functional role of cardiolipin. 668 Prog Lipid Res 39: 257-288.

669 Schlame M, Ren M (2006) Barth syndrome, a human disorder of cardiolipin metabolism. $670 \quad$ FEBS Lett 580: 5450-5455.

671 Shaw BL, Battle HI (1957) The gross microscopic anatomy of the digestive tract of the oyster 672 Crassostrea virginica (Gmelin). Can J Zool 35: 325-346.

673 Shumway SE, Barter J, Stahlnecker J (1988) Seasonal changes in oxygen consumption of the 674 giant scallop, Placopecten magellanicus (Gmelin). J Shell Res 7: 77-82.

675 Smith PK, Krohn RI, Hermanson GT, Mallia AK, Gartner FH, Provenzano MD, Fujimoto 676 EK, Goeke NM, Olson BJ, Klenk DC (1985) Measurement of protein using 677 bicinchoninic acid. Anal Biochem 150: 176-185. 
678 Soletchnik P, Razet D, Geairon P, Faury N, Goulletquer P (1997) Ecophysiology of

679

680

681

682

683

684

685

686

687

688

689

690

691

692

693

694

695

696

697

698

699

700

701

702

703

704

705 maturation and spawning in oyster (Crassostrea gigas): metabolic (respiration) and feeding (filtration and absorption rates) responses at different maturation stages. Aquat Living Resour 10: 177-185.

Soudant P, Marty Y, Moal J, Robert R, Quéré C, Le Coz JR, Samain JF (1996) Effect of food fatty acids and sterol quality on Pecten maximus gonad composition and reproduction process. Aquaculture 143: 361-378.

Thompson RJ, Livingstone DR, de Zwaan A (1980) Physiological and biochemical aspects of valve snap and valve closure responses in the giant scallop Placopecten magellanicus. I. Physiology. J Comp Physiol 137: 97-104.

Tran D, Massabuau JC, Vercelli C (2008) Influence of sex and spawning status on oxygen consumption and blood oxygenation status in oysters Crassostrea gigas in a Mediterranean lagoon (Thau, France). Aquaculture 277: 58-65.

Tremblay I, Guderley H, Fréchette M (2006) Swimming performance, metabolic rates, and their correlates in the iceland scallop Chlamys islandica. Physiol Biochem Zool 79: 1046-1057.

Watkins SM, Carter LC, German JB (1998) Docosahexaenoic acid accumulates in cardiolipin and enhances HT-29 cell oxidant production. J Lipid Res 39: 1583-1588.

Williams JN (1964) A method for the simultaneous quantitative estimation of cytochromes A, B, $\mathrm{C} 1$ and $\mathrm{C}$ in mitochondria. Arch Biochem Biophys 107: 537-543.

Wodtke E (1981) Temperature adaptation of biological membranes. The effects of acclimatation temperature on the unsaturation of the main neutral and charged phospholipids in mitochondrial membranes of the carp (Cyprinus carpio L.). Biochim Biophys Acta 640: 698-709.

Yamaoka S, Urade R, Kito M (1988) Mitochondrial function in rats is affected by modification of membrane phospholipids with dietary sardine oil. J Nutr 118: 290296. 
Figure 1: Gamete volume fraction (GVF) and gonadosomatic index (GSI; gonad wet mass/ total tissue mass) of scallops sampled at different reproductive stages. GSI was determined for males and females while GVF was only determined for females. Values are means \pm s.e.m. (GVF: $\mathrm{N}=7$ for pre-spawned scallops, $\mathrm{N}=3$ for spawned and $\mathrm{N}=5$ for reproductive-quiescent scallops; GSI: N=8 for pre-spawned scallops, $\mathrm{N}=7$ for spawned and reproductive-quiescent scallops). Different letters indicate values that differ between dates and hence reproductive stages (ANOVA and a posteriori test, $\mathrm{P}<0.05$ ).

Figure 2: Escape responses performance as a function of reproductive status of Placopecten magellanicus. A) Time before first reaction, B) maximum number of claps in a series, C) total number of claps and D) total escape time before exhaustion for scallops at the different reproductive stages. Values are means \pm s.e.m. ( $N=9$ for pre-spawned and spawned scallops, $\mathrm{N}=8$ for reproductive-quiescent scallops). Different letters indicate values that differ between reproductive stages (ANOVA and a posteriori test, $\mathrm{P}<0.05$ ).

Figure 3: Standard metabolic rates $\left(\mathrm{VO}_{2} \mathrm{~min}\right)$ and metabolic rates after exhaustion $\left(\mathrm{VO}_{2} \mathrm{max}\right)$ for scallops at different reproductive stages. Values are means \pm s.e.m. ( $N=9$ for pre-spawned and spawned scallops, $\mathrm{N}=8$ for reproductive-quiescent scallops). Different letters indicate values that differ between reproductive stages (ANOVA and a posteriori test, $\mathrm{P}<0.05$ ).

726

Figure 4: Ratio of standard metabolic rate to maximal $\mathrm{VO}_{2}$ and maximum minus standard metabolic rates $\left(\mathrm{VO}_{2} \max -\mathrm{VO}_{2} \mathrm{~min}\right)$ for scallops at different reproductive stages. Values are means \pm s.e.m. ( $\mathrm{N}=9$ for pre-spawned and spawned scallops, $\mathrm{N}=8$ for reproductive-quiescent scallops). Different letters indicate values that differ between reproductive stages (ANOVA and a posteriori test, $\mathrm{P}<0.05)$.

734 Figure 5: State 3 respiratory rates $\left(\mathrm{nmol}\right.$ O. $\mathrm{min}^{-1}$ ) expressed over concentrations of 735 cytochromes and ANT $\left(\mathrm{nmol}^{-1}\right)$ in mitochondria isolated from the muscle of scallops at 736 different reproductive stages (assay temperature, $\left.5^{\circ} \mathrm{C}\right)$. Values are means \pm s.e.m. $(\mathrm{N}=8$ for 737 pre-spawned scallops, $\mathrm{N}=7$ for spawned and reproductive-quiescent scallops). Different 
738 letters indicate rates that differ between reproductive stages (ANOVA and a posteriori test, $739 \quad \mathrm{P}<0.05)$.

740

741 Figure 6: Cytochrome $C$ oxidase (CCO) activity in muscle mitochondria isolated from 742 scallops at different reproductive stages, expressed in $\mathrm{U}_{\mathrm{CCO}} \mathrm{mg}^{-1}$ mitochondrial protein and $743 \mathrm{U}_{\mathrm{CCO}} \mathrm{nmol}^{-1}$ cytochrome $\mathrm{A}$, measured at $5^{\circ} \mathrm{C}$ (white bars) and $15^{\circ} \mathrm{C}$ (grey bars) $744\left(\mathrm{U}_{\mathrm{CCO}}=\mu \mathrm{mol}\right.$ cytochrome $c$ reduced $\left.\min ^{-1}\right)$. Values are means \pm s.e.m. $(\mathrm{N}=8$ for pre-spawned 745 and spawned scallops and $\mathrm{N}=7$ for reproductive-quiescent scallops). Different letters indicate 746 rates that differ between reproductive stages at a given assay temperature (ANOVA and $a$ 747 posteriori test, $\mathrm{P}<0.05)$.

748

749 Figure 7: Classes and subclasses of phospholipids from the mitochondrial fraction isolated 750 from scallop muscle at different reproductive stages. Phospholipids are expressed as mol\% of 751 total moles of glycerophospholipids. Values are means \pm s.e.m. ( $N=4$ for each stage). No 752 significant differences were noted between reproductive stages (two-way factorial 753 MANOVA, least square means multiple comparison tests, $\mathrm{P}<0.05$ ).

754 *diacyl form of phosphatidylserine (PS), phosphatidylethanolamine (PE) and 755 phosphatidylcholine (PC).

$756 * *$ plasmalogen (1-alkenyl-2-acyl-) form of phosphatidylethanolamine (PE). The plasmalogen 757 forms of PC and PS were also detectable but only in trace amounts $(<0.5 \mathrm{~mol} \%)$. 758

759 Figure 8: Main fatty acid composition of cardiolipin (CL) in mitochondrial fractions isolated 760 from scallop muscle at different reproductive stages. Values are means \pm s.e.m. $(\mathrm{N}=4$ for each 761 stage). Different letters indicate values that differ between reproductive stages (two-way 762 factorial MANOVA, least square means multiple comparison tests, $\mathrm{P}<0.05$ ). 763 764 
764 Table 1: Recuperation (\%) of total claps and escape time after 30 min following exhausting 765 exercise for scallops in the different reproductive states. Values are means \pm s.e.m. $(\mathrm{N}=9$ for 766 pre-spawned and spawned scallops, $\mathrm{N}=8$ for reproductive-quiescent scallops). Different 767 superscripts indicate differences between reproductive stages (ANOVA and a posteriori test, $768 \mathrm{P}<0.05)$.

769

\begin{tabular}{|lccc|}
\hline \% Recovery & Pre-spawned & Spawned & Reproductive quiescent \\
\hline Total claps & $75.2 \pm 9.8$ & $56.2 \pm 7.6$ & $67.8 \pm 8.1$ \\
Escape time & $84.5 \pm 11.1^{\mathrm{a}}$ & $53.3 \pm 7.3^{\mathrm{b}}$ & $81.7 \pm 5.1^{\mathrm{a}}$ \\
\hline
\end{tabular}

770

771 
771 Table 2: Oxidative capacities at $5^{\circ} \mathrm{C}$ of muscle mitochondria from scallops in different 772 reproductive stages. State 3 and state 4 rates of glutamate oxidation are expressed as nmol 773 O. $\mathrm{min}^{-1} \cdot \mathrm{mg}^{-1}$ mitochondrial protein. Values are means \pm s.e.m. ( $\mathrm{N}=8$ for pre-spawned 774 scallops, $\mathrm{N}=7$ for spawned and reproductive-quiescent scallops). No significant differences 775 were noted between reproductive stages.

\begin{tabular}{|lccc|}
\hline & Pre-spawned & Spawned & Reproductive quiescent \\
\hline State 3 & $46.3 \pm 4.6$ & $53.5 \pm 3.8$ & $53.0 \pm 3.6$ \\
State 4 & $8.9 \pm 1.3$ & $7.7 \pm 0.7$ & $9.1 \pm 0.6$ \\
ADP/O & $2.5 \pm 0.2$ & $2.6 \pm 0.1$ & $2.3 \pm 0.1$ \\
\hline
\end{tabular}

776

777 
777 Table 3: Concentration of cytochromes and ANT in scallop muscle mitochondria at different

778 reproductive stages. Cytochrome and ANT concentrations were normalized to the protein

779 content in the mitochondrial preparations. Values are means \pm s.e.m. ( $N=9$ for pre- and

780 spawned scallops, $\mathrm{N}=8$ for reproductive-quiescent scallops). Different superscripts indicate

781 values that differ between reproductive stages (ANOVA and a posteriori test, $\mathrm{P}<0.05$ ).

782

783

\begin{tabular}{|lccc|}
\hline & Pre-spawned & Spawned & Reproductive quiescent \\
\hline A & $0.23 \pm 0.03$ & $0.18 \pm 0.01$ & $0.22 \pm 0.03$ \\
B & $0.1 \pm 0.01^{\mathrm{a}}$ & $0.16 \pm 0.02^{\mathrm{b}}$ & $0.15 \pm 0.01^{\mathrm{ab}}$ \\
$\mathrm{C}_{1}$ & $0.16 \pm 0.02$ & $0.11 \pm 0.01$ & $0.15 \pm 0.01$ \\
C & $0.05 \pm 0.01^{\mathrm{a}}$ & $0.05 \pm 0.01$ & $0.04 \pm 0.01$ \\
ANT & $0.66 \pm 0.07^{\mathrm{a}}$ & $0.75 \pm 0.02^{\mathrm{a}}$ & $1.05 \pm 0.05^{\mathrm{b}}$ \\
\hline
\end{tabular}

784 
784 Table 4: Content of cholesterol, total phospholipids and phospholipid classes and subclasses 785 in mitochondrial fractions isolated from scallop muscle at different reproductive stages.

786 Values are means \pm s.e.m. $(\mathrm{N}=4$ for each stage). Different superscripts indicate values that 787 differ between reproductive stages (ANOVA and a posteriori test, $\mathrm{P}<0.05$ )

788

\begin{tabular}{lccc}
\hline & Pre-spawned & Spawned & $\begin{array}{c}\text { Reproductive } \\
\text { quiescent }\end{array}$ \\
\hline Total glycerophospholipids $\left(\mu \mathrm{mol}_{\mathrm{mg}} \mathrm{m}^{-1}\right.$ prot $)$ & $0.31 \pm 0.03$ & $0.37 \pm 0.02$ & $0.38 \pm 0.08$ \\
Sterols $\left(\mu \mathrm{mol}_{\mathrm{m}}{ }^{-1}\right.$ prot$)$ & $0.16 \pm 0.03$ & $0.18 \pm 0.02$ & $0.19 \pm 0.01$ \\
\% Sterols & $34.1 \pm 1.3$ & $33.1 \pm 2.8$ & $31.8 \pm 4.1$ \\
& & & \\
$\quad$ Classes and subclasses (nmol.mg & & \\
CL & & & \\
PS & $1.7 \pm 0.2$ & $2.1 \pm 0.2$ & $1.9 \pm 0.3$ \\
DiacylPE & $12.9 \pm 0.9$ & $15.9 \pm 1.2$ & $14.2 \pm 3.4$ \\
PlsmPE & $34.8 \pm 2.9$ & $35.9 \pm 2.2$ & $39.4 \pm 8.7$ \\
DiacylPC & $15.9 \pm 3.5$ & $16.4 \pm 1.0$ & $19.7 \pm 3.6$ \\
PI & $90.9 \pm 12.9$ & $114.8 \pm 7.5$ & $104.9 \pm 22.9$ \\
\hline
\end{tabular}


790 Table 5: FA composition of total phospholipids in mitochondrial fractions isolated from 791 scallop muscle at the different reproductive stages. Results are expressed as mol\%. Values are 792 means \pm s.e.m. ( $\mathrm{N}=4$ for each stage). Different superscripts indicate values that differ between 793 reproductive stages (two-way factorial MANOVA, least square means multiple comparisons, $794 \mathrm{P}<0.05)$.

$795 *$ Others : Total of 19 detectable fatty acids (iso17:0, ant17:0, 15:0, 17:0, 16:1n-5, 18:1n-5, 18:2n-4, 18:3n-6, 796 18:3n-3, 20:2nmi(5,11), 20:2nmi(5,13), 20:3nmi(5,11,14), 20:2n-6, 20:3n-6, 20:4n-3, 21:5n-3, 22:2nmi(7,13), $797 \quad 22: 2 \mathrm{nmi}(7,15), 22: 3 \mathrm{nmi}(7,13,16), 22: 4 \mathrm{n}-6)$, none of which exceeded $1.0 \%$.

$798 * *$ Total dimetylacetals (mainly 16:0DMA, 18:0DMA and 20:1DMA).

799

\begin{tabular}{|c|c|c|c|}
\hline \multirow[b]{3}{*}{ Fatty acids } & \multicolumn{3}{|c|}{ Total Phospholipids } \\
\hline & Pre-Spawned & Spawned & Reproductive quiescent \\
\hline & & & \\
\hline $14: 0$ & $2.0 \pm 0.4$ & $2.3 \pm 0.2$ & $2.0 \pm 0.1$ \\
\hline $16: 0$ & $18.7 \pm 0.5$ & $19.6 \pm 0.2$ & $19.1 \pm 0.9$ \\
\hline $18: 0$ & $4.9 \pm 0.2^{\mathrm{a}}$ & $4.6 \pm 0.1^{\mathrm{a}}$ & $6.2 \pm 0.5^{b}$ \\
\hline $16: 1 n-7$ & $2.8 \pm 0.3$ & $3.2 \pm 0.2$ & $2.6 \pm 0.2$ \\
\hline $18: 1 n-9$ & $1.8 \pm 0.1$ & $1.8 \pm 0.1$ & $1.8 \pm 0.1$ \\
\hline $18: 1 n-7$ & $5.7 \pm 0.2$ & $6.0 \pm 0.2$ & $5.5 \pm 0.2$ \\
\hline $20: 1 n-11$ & $0.4 \pm 0.1^{\mathrm{a}}$ & $0.5 \pm 0.1^{\mathrm{ab}}$ & $0.6 \pm 0.1^{\mathrm{b}}$ \\
\hline $20: 1 n-9$ & $0.5 \pm 0.05$ & $0.5 \pm 0.02$ & $0.6 \pm 0.02$ \\
\hline $20: 1 n-7$ & $0.6 \pm 0.1$ & $0.6 \pm 0.04$ & $0.6 \pm 0.02$ \\
\hline $18: 2 n-6$ & $0.6 \pm 0.03$ & $0.9 \pm 0.1$ & $0.9 \pm 0.04$ \\
\hline $18: 4 n-3$ & $3.0 \pm 0.2^{\mathrm{a}}$ & $2.0 \pm 0.2^{\mathrm{b}}$ & $2.0 \pm 0.2^{\mathrm{b}}$ \\
\hline $20: 4 n-6$ & $1.0 \pm 0.1^{\mathrm{a}}$ & $1.2 \pm 0.1^{\mathrm{ab}}$ & $1.4 \pm 0.1^{\mathrm{b}}$ \\
\hline $20: 5 n-3$ & $24.5 \pm 0.7$ & $22.8 \pm 0.7$ & $22.7 \pm 0.4$ \\
\hline $22: 5 n-6$ & $0.3 \pm 0.01^{\mathrm{a}}$ & $0.4 \pm 0.01^{b}$ & $0.4 \pm 0.02^{b}$ \\
\hline $22: 5 n-3$ & $0.9 \pm 0.1$ & $0.8 \pm 0.02$ & $0.8 \pm 0.05$ \\
\hline $22: 6 n-3$ & $21.3 \pm 0.3$ & $21.8 \pm 0.3$ & $21.3 \pm 0.6$ \\
\hline Others* & $6.4 \pm 0.7$ & $6.4 \pm 0.2$ & $5.5 \pm 0.2$ \\
\hline $\mathrm{DMA}^{* *}$ & $4.6 \pm 0.7$ & $4.3 \pm 0.5$ & $5.0 \pm 0.2$ \\
\hline Total SFA & $27.8 \pm 1.1$ & $29.2 \pm 0.3$ & $30.3 \pm 1.6$ \\
\hline Total MUFA & $13.4 \pm 0.4$ & $13.9 \pm 0.3$ & $12.5 \pm 0.6$ \\
\hline Total PUFA & $54.2 \pm 1.0$ & $52.7 \pm 0.5$ & $52.2 \pm 1.1$ \\
\hline UI & $295.9 \pm 5.0$ & $288.9 \pm 2.9$ & $284.2 \pm 6.4$ \\
\hline
\end{tabular}

800 